\title{
Dynamic Analysis of the Evolution of Cereus peruvianus (Cactaceae) Areas Attacked by Phoma sp.
}

\author{
Gyorgy FESZT ${ }^{1)}$, Lucica MIHALTE2), Radu SESTRAS ${ }^{2)}$ \\ 1) Alexandru Borza Botanical Garden, 42 Republicii Street, Cluj-Napoca, Romania; fesztgy@gmail.com \\ 2) University of Agricultural Sciences and Veterinary Medicine, Faculty of Horticulture, 3-5 Manastur Street, \\ 3400,Cluj-Napoca,Romania; Imihalte@notulaebotanicae.ro; rsestras@notulaebotanicae.ro
}

\begin{abstract}
Cereus Peruvianus (night blooming Cereus, or peruvian apple) is one of the sensitive species to Phoma attack. Photographic images can intercept a certain phytopathology, at a certain moment. The computerized analysis of such an image turns into a value the spread which the phytopathological process has at that moment. The purpose of this study is to assimilate the technique of achieving successions of digital photos of Cereus peruvianus f. monstruosa attacked by Phoma sp. Parallely with recording the images, with the help of Rhythm digital temperature humidity controller, were recorded data about the green house microclimate (air humidity-minimum and maximum, temperature-minimum and maximum). In the first stage of the study, the attack presents small fluctuations, reaching a high level in days with low temperatures. So, the most significant growths were recorded in the periods: 10. 02. 2005-20. 02. 2005 with an affected area of $10.97-8.82=2.15$ and 11. 03. 2005-22. 04. 2005 with growth differences of 14.67-13.32 $=1.35$. Generally, the affected areas grow in days with low minimum temperatures. The great advantage of this technique is represented by the possibility of using in situ in home areas of species or crop plants in fields. Repeated images, achieved in time, then overlapped, can provide important data on the evolution of affected areas.
\end{abstract}

Keywords: cacti disease, photographic image, Phoma sp., Cereus peruvianus f. monstruosa

\section{Introduction}

Cacti are original from the American continent. In the vast habitat occupied by the Cactaceae family, which ranges between 35 degrees North latitude in Canada and 54 degrees South latitude, in the region of Magellan strait, where environment conditions are extremely varied. These impress plants certain morph-biological particularities, which, actually, represent plants adaptations to environmental conditions, more or less favourable (Copacescu, 2001).

Many authors, including Ridings, 1978; Miller, 1980; Rosciglione, 1980; Anson, 1982; Chase 1982; Arnold, 1986; Nakhutsrishvili, 1986; Simay, 1987; Turner, 1992; Glang, 1993; Chavez, 1998; Anderson, 1999; Kobayashi, 2000; Swart et al., 2002, describe cacti multitude of diseases. Feszt et al., 2006, has published diameter measurements of the viruses extracted from Cactaceae vegetative multiplied from Cluj-Napoca Botanical Garden (Romania) collection.

The most important cacti diseases can be grouped according to their pathogenic agents: bacterial diseases $(E r-$ winia carotovora, Erwinia cacticida, Agrobacterium tumefaciens), yeast diseases (Candida boidimi), fungal diseases
(Armillaria mellea, Alternaria alternata, Phytophthora cactorum, Phytophthora nicotianae, Botrytis cinerea, Pleospora herbanum, Sclerotinia sclerotium, Fusarium oxysporum, Gleosporium herbarum), phytoplasmalike and viruslike disease (Nobel, 2002).

Phytopathological processes are dynamics processes, which evolve in time, with different speeds according to various factors, usually environmental.

Photographic images may surprise a certain phytopathological aspect, at a certain moment. The computerized analysis of such an image turns into a number the spread which the phytopathological process has at that moment.

In order to have a dynamic image of the phytopathological process, successions of images are necessary, each of them will be analyzed separately, manually or automatically.

\section{Materials and methods}

The Cactaceae collection from Cluj-Napoca Botanical Garden (Romania) counts more than 4100 plants belonging to 115 genera, from the 241 total known, after the Backeberg system (Backeberg 1962, 1966, 1968). 
42

Cacti from private collection cactuses or from Botanical Gardens are cultivated in artificial conditions, with specific microclimate, which assures optimum of physical parameters. Under these circumstances plants are less resistant and have a high sensibility to diseases and pests attacks.

The purpose of this study is to assimilate the technique of achieving digital photos successions and two methods of analysis for produced digital images.

Cereus peruvianus f. monstruosa with Phoma sp. (Pleosporales) attack, was chosen as a study subject. Cereus peruvianus picks up the common name, apple cactus because of its 1-2 inch fleshy, red apple like fruit.

Phoma genus has colorless and unicellular spores. The pycnidia are black and depressed in the tissues of the host.

In order to photograph in succession the same surface, a Panasonic DMC-FZ2E digital camera, which allows macro photography and has image stabilizer in order to remove trepidation moves, has been chosen. Because we don't know the surfaces which are going to be attacked by disease, for study, areas at random were chosen. These were bounded through particular signs, stuck or glued (Fig. 1.).

Cacti portions were successively photographed every 10 days, thus creating a chain of digital images. In processing images Adobe Photoshop was used, because any digital image, stored in a computer as a folder in any format (jpg. tiff, gif, bmp, png) is, actually, formed by a higher or smaller number of pixels, according to the resolution image.

The working method was used in human medicine by Gamal (2004) and Gheban (2005) and was adapted in phytopathology in this study with the purpose of quantifying growth speed of areas affected by diseases or pests.

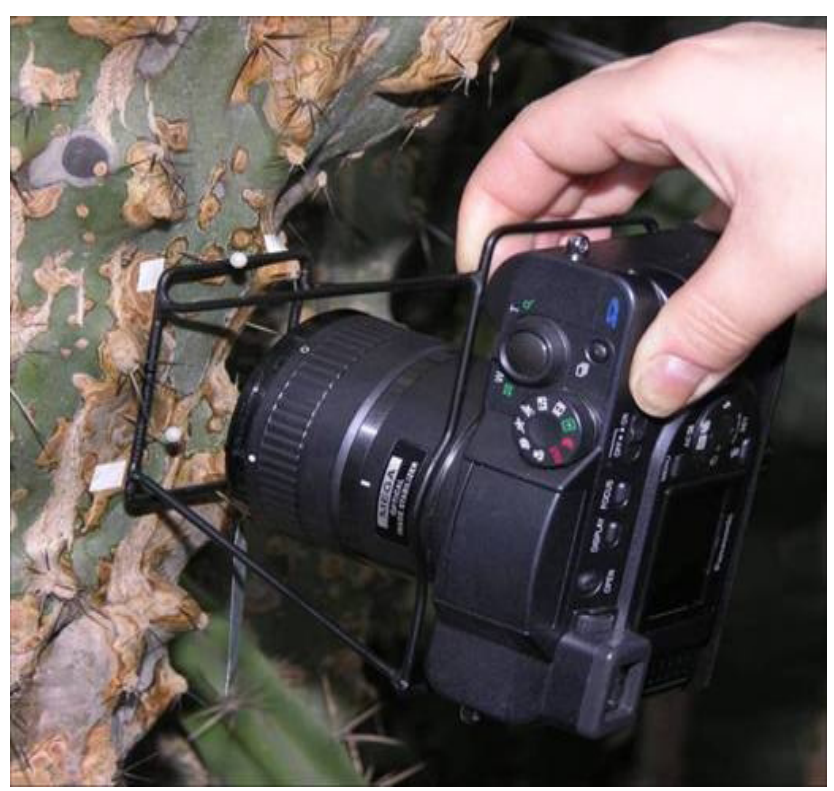

Fig. 1. The moment of photograph with particular overt signs stiff or attached for defining the study area
Parallel with images capture, with the help of Rhythm digital temperature humidity controller, was recorded data concerning the green house microclimate. The controller is equipped with sensors for recording relative air humidity between 10 and $95 \%$ of temperature with the help of 2 sensors, one at the soil level, incorporated in the apparatus, and an extension which measures the temperature at the higher level of the green house. The sensor at height was placed in the interior of a white recipient in order to be protected against solar rays. The apparatus shows actual temperature and humidity as well as maximums and minimums memorized from the last memory deletion.

\section{Results and disscusion}

The exact number of pixels (total number of pixels) of an image can be searched out in Adobe Photoshop by using "Histogram" function, available in the "Image" window of the program. Adobe Photoshop allows manual or automatic selection of a certain interest area from the picture. For manual selection we can use "Lasso Tool" (Fig. 2)

Automatic selection can be operated using "Color Range" command from the "Select" window of the program. This command selects a specified color or color range within the image. For this purpose, it is necessary to obtain a very specific colored image for the element desired to be analyzed.

Once the selection is made (manually or automatically), the exact dimension of the selection, in number of selected pixels is obtained by using again "Histogram" command.

This time, "Histogram" command will display only the number of selected pixels. Utilizing this number, we can find out the percentage representing the selected areas from the total, using the rule of three, like in the follow example:

1920000 (total number of pixels) $100 \%$

501303 (selected number of pixels) .. $\mathrm{x} \%$ $\mathrm{x}=26.10 \%$

Similar results are obtained through $3 \mathrm{D}$ Houdini Aprentice which is an animation program and as a command has the possibility to calculate area, surface. With help of animation program it has been created a range of overlap images, which represent the dynamic growth express in percentage (Fig. 4).

Temperatures were read with digital temperature humidity capture every day at the same hour (winter-13:30, summer-14:30), noting minimum-maximum air humidity, minimum-maximum temperature. (Tab. 1)

In early experience, affected areas growths were more accentuated in comparison with the similar period of next year.

Average of minimum temperatures in 10.02. 2005-02. 05. 2005 was $15.8^{\circ}$ C. Correlated with 13 . 02. 2006-08 


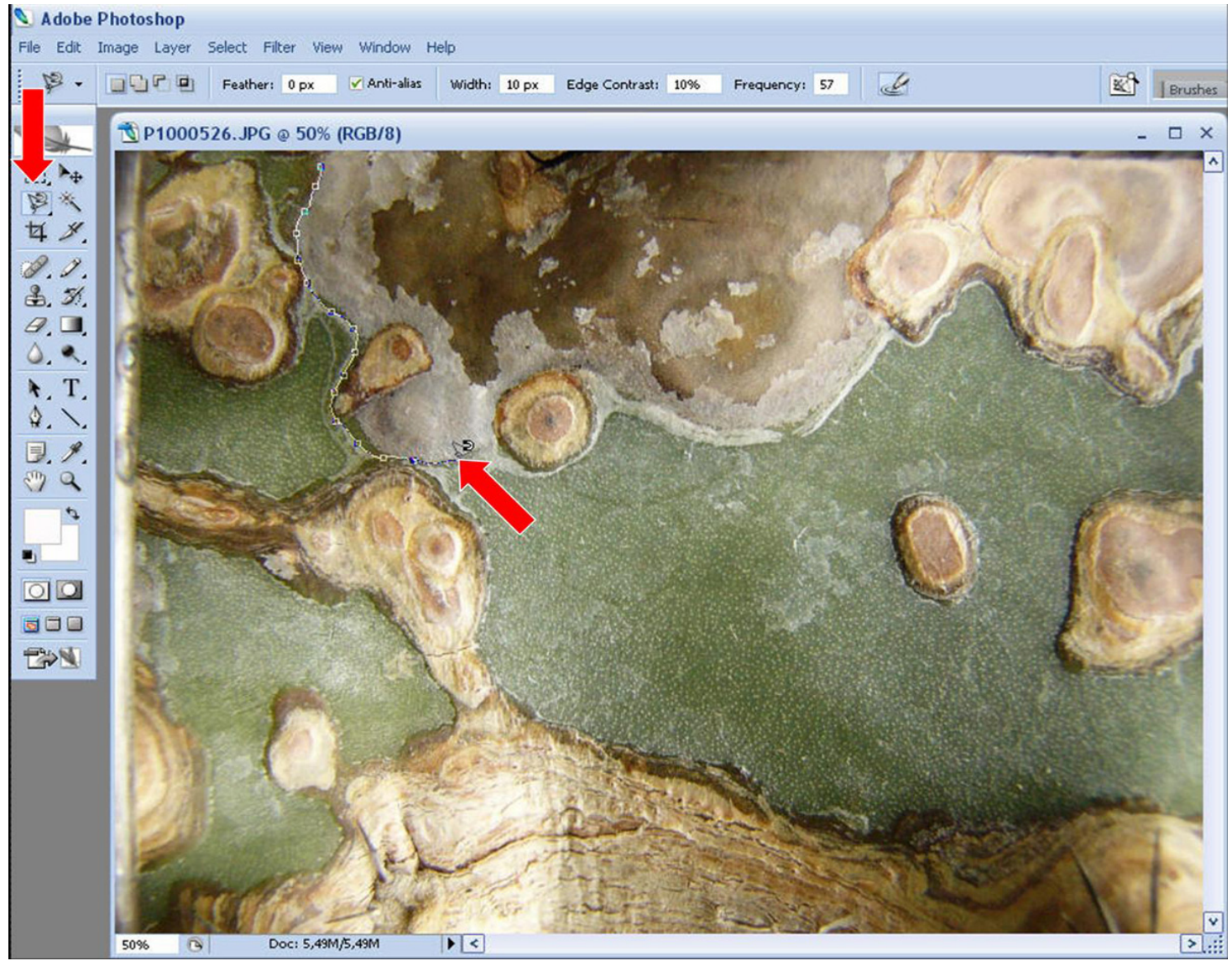

Fig. 2. Manual selection of any area from the image using "Lasso Tool"

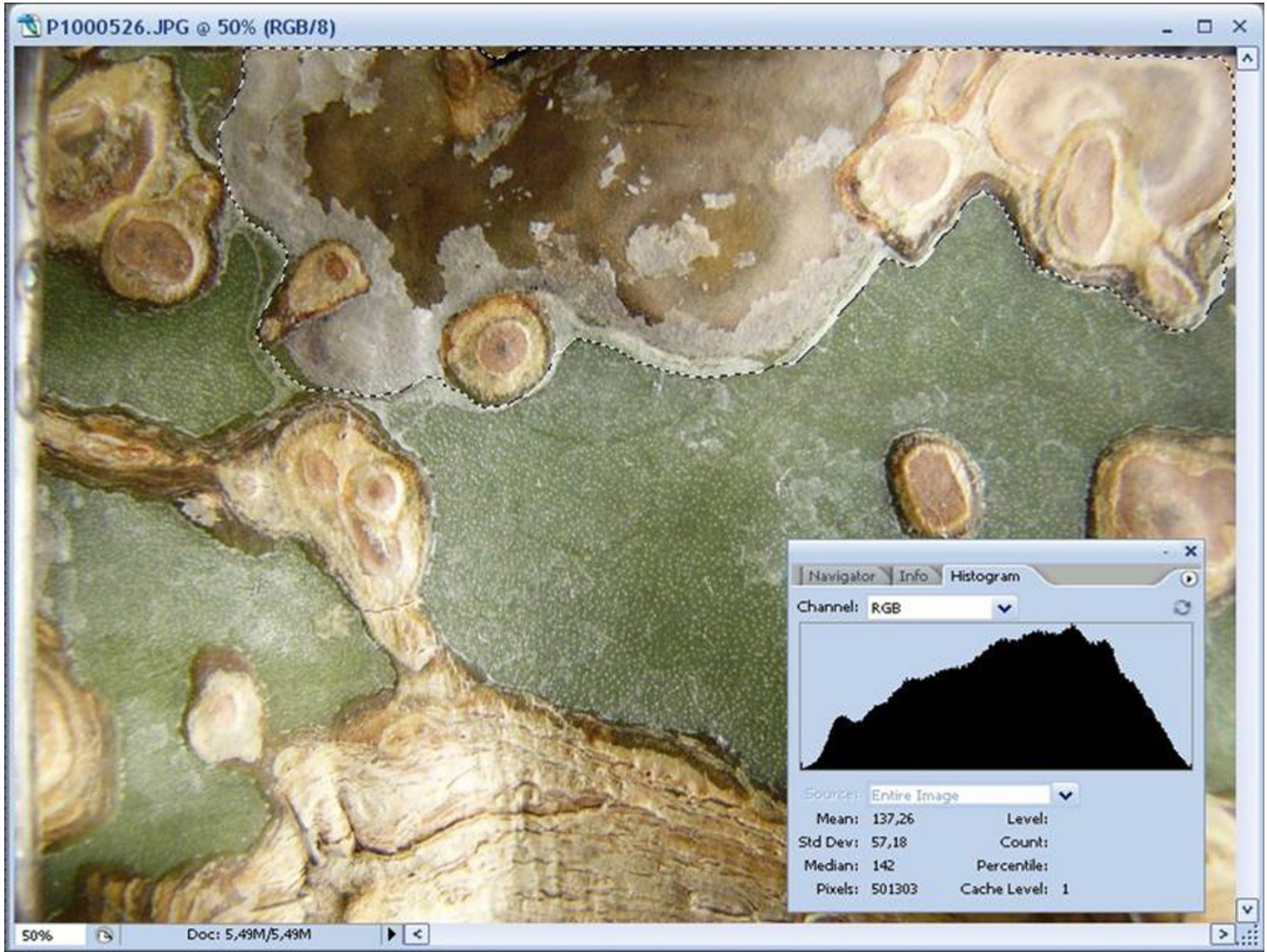

Fig. 3. The number of selected pixels displayed in the "Histogram" window. 
44

Tab. 1. Temperature and humidity correlation with the affected area (Cereus peruvianus) by mycosis (Phoma sp.)

\begin{tabular}{|c|c|c|c|c|c|}
\hline Date & $\operatorname{Min}$ T. $C^{\circ}$ & $\operatorname{Max}$ T. $C^{\circ}$ & Min H. \% & Max H. \% & Area \% \\
\hline 10.02 .2005 & 12.53 & 27.41 & 27.55 & 43.66 & 8.82 \\
\hline 20.02 .2005 & 15.22 & 24.89 & 36.09 & 50.27 & 10.97 \\
\hline 01.03 .2005 & 15.97 & 28.09 & 34.40 & 55.40 & 12.05 \\
\hline 11.03 .2005 & 13.74 & 32.17 & 26.54 & 56.45 & 13.32 \\
\hline 22.03 .2005 & 16.11 & 34.04 & 24.66 & 64.41 & 14.67 \\
\hline 02.04 .2005 & 17.39 & 37.83 & 21.41 & 61.25 & 15.73 \\
\hline 11.04 .2005 & 16.74 & 38.09 & 18.20 & 58.7 & 16.82 \\
\hline 21.04 .2005 & 18.72 & 34.52 & 31.54 & 69.27 & 17.86 \\
\hline 02.05 .2005 & 17.47 & 32.95 & 29.00 & 62.66 & 18.01 \\
\hline 11.05 .2005 & 16.96 & 04.34 & 28.0 & 70.5 & 18.09 \\
\hline 24.05 .2005 & 16.24 & 32.82 & 35.64 & 75.28 & 18.55 \\
\hline 01.06 .2005 & 18.97 & 40.33 & 28.77 & 82.33 & 18.63 \\
\hline 13.06 .2005 & 15.68 & 34.11 & 32.23 & 77.69 & 19.08 \\
\hline 22.06 .2005 & 18.65 & 39.37 & 25.1 & 76.0 & 19.12 \\
\hline 02.07 .2005 & 19.55 & 39.79 & 23.90 & 72.63 & 19.44 \\
\hline 12. 07.2005 & 20.08 & 35.59 & 39.81 & 78.0 & 19.55 \\
\hline 22.07 .2005 & 19.16 & 36.47 & 41.36 & 83.0 & 19.68 \\
\hline 02.08 .2005 & 20.43 & 40.67 & 29.83 & 80 & 19.80 \\
\hline 12. 08.2005 & 19.92 & 34.94 & 40 & 82.81 & 20.18 \\
\hline 23.08 .2005 & 18.64 & 33.95 & 34.41 & 84.75 & 20.53 \\
\hline 02. 09.2005 & 18.63 & 34.54 & 44.63 & 90.54 & 20.64 \\
\hline 13.09 .2005 & 16.48 & 33.46 & 31.58 & 81.58 & 20.84 \\
\hline 23.09 .2005 & 15.94 & 29.99 & 49.18 & 86.90 & 20.91 \\
\hline 03.10 .2005 & 15.99 & 29.94 & 43.45 & 84.63 & 21.27 \\
\hline 13. 10.2005 & 14.69 & 30.12 & 32 & 70 & 21.31 \\
\hline 24. 10.2005 & 15.28 & 28.57 & 35.41 & 59.66 & 21.33 \\
\hline 03.11 .2005 & 15.10 & 29.72 & 28.90 & 60.18 & 21.47 \\
\hline 14.11 .2005 & 15.25 & 25.7 & 33.75 & 53.83 & 21.51 \\
\hline 24.11.2005 & 15.7 & 23.54 & 32.90 & 47.81 & 21.63 \\
\hline 05.12 .2005 & 16.88 & 24.05 & 34.33 & 51.16 & 21.76 \\
\hline 14. 12.2005 & 16.80 & 24.72 & 33.1 & 52.7 & 21.81 \\
\hline 25.12 .2005 & 15.02 & 22.03 & 30.66 & 51.66 & 21.87 \\
\hline 05.01 .2006 & 16.55 & 22.39 & 32.5 & 46.16 & 21.98 \\
\hline 16. 01.2006 & 15.34 & 23.67 & 27.08 & 40.58 & 22.01 \\
\hline 24.01 .2006 & 14.35 & 22.49 & 25.66 & 38.88 & 22.03 \\
\hline 03.02 .2006 & 13.40 & 22.94 & 29.81 & 41.81 & 22.07 \\
\hline 13.02. 2006 & 14.87 & 24.33 & 27.09 & 45 & 22.08 \\
\hline 24. 02.2006 & 15.19 & 27.58 & 25.75 & 55.16 & 22.11 \\
\hline 03.03 .2006 & 14.27 & 25.99 & 27.5 & 57.75 & 22.24 \\
\hline 06.03 .2006 & 16.55 & 29.35 & 25 & 51.75 & 22.28 \\
\hline 16.03.2006 & 16.05 & 28.49 & 23 & 56.27 & 22.30 \\
\hline 27.03 .2006 & 16.55 & 32.00 & 20.58 & 50.83 & 22.31 \\
\hline 06.04 .2006 & 18.34 & 33.29 & 21.63 & 61.54 & 22.33 \\
\hline 17.04 .2006 & 17.44 & 32.09 & 25.66 & 68 & 22.34 \\
\hline 28.04.2006 & 17.91 & 37.22 & 21.16 & 70.83 & 22.35 \\
\hline 08.05 .2006 & 10.86 & 36 & 17.63 & 63.81 & 22.36 \\
\hline 18.05 .2006 & 11.68 & 35.46 & 21.81 & 74.63 & 22.37 \\
\hline 29.05 .2006 & 14.21 & 37.4 & 22.41 & 80.91 & 22.38 \\
\hline 08.06 .2006 & 11.59 & 31.85 & 27.45 & 86.09 & 22.39 \\
\hline 19.06. 2006 & 14.22 & 38.25 & 20.83 & 79.25 & 22.41 \\
\hline 29.06 .2006 & 19.61 & 44.79 & 12 & 67.1 & 22.42 \\
\hline 10.07.2006 & 19.32 & 39.29 & 16.5 & 64.66 & 22.43 \\
\hline 20.07 .2006 & 16.59 & 37.31 & 17.27 & 63.81 & 22.44 \\
\hline 30.07 .2006 & 20.08 & 42.26 & 15 & 55.81 & 22.45 \\
\hline 09.08 .2006 & 18.54 & 37.82 & 20.92 & 70.45 & 22.47 \\
\hline
\end{tabular}
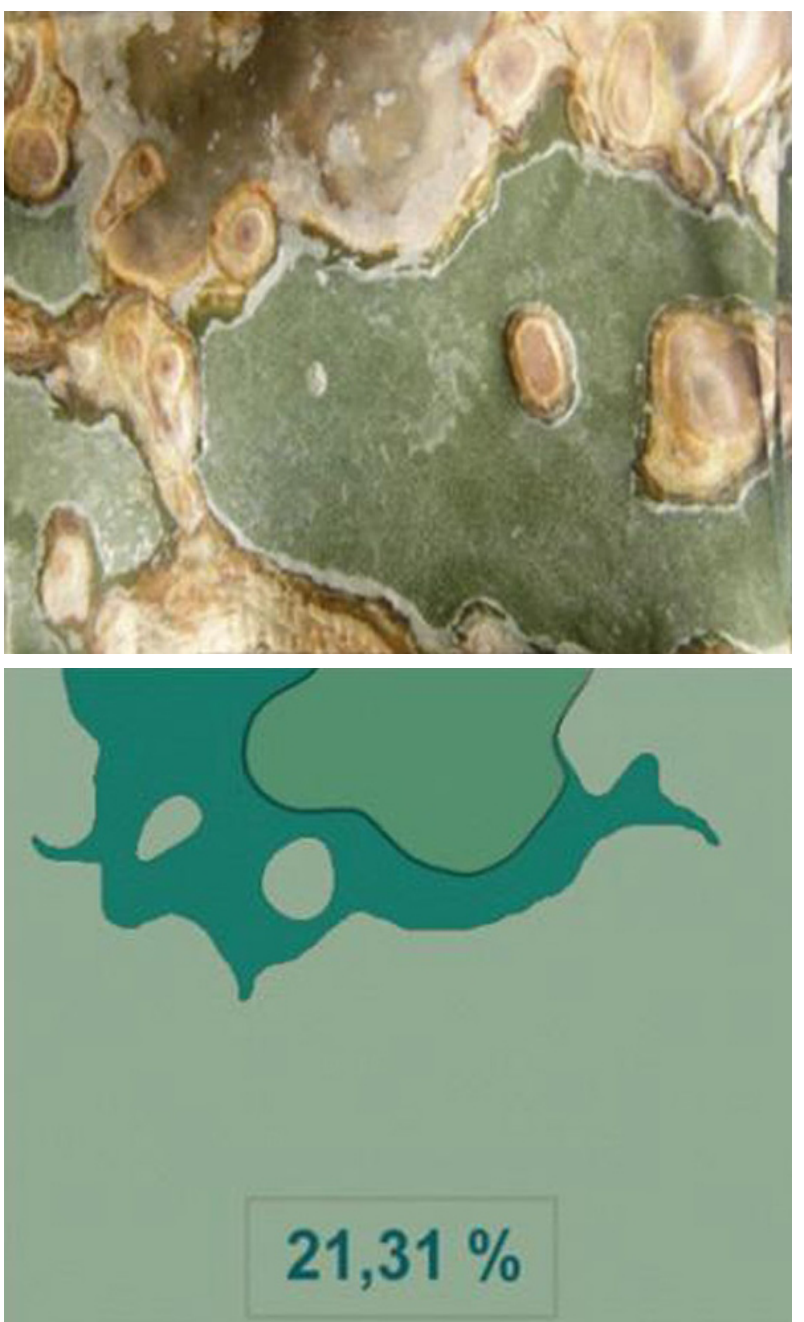

Fig. 4. Illustration with animation framework

05. 2006 period with temperatures of $15.9^{\circ} \mathrm{C}$ gave a small difference of $0.1^{\circ} \mathrm{C}$. (Tab. 1)

The maximum values of the compared periods of $30.6^{\circ}$ and $32.2^{\circ} \mathrm{C}$ present a substantial growth of $1.6^{\circ} \mathrm{C}$ in 2006 as compared to 2005.

Although the studied areas were chosen randomly, in the first period of the study, the attack presents small fluctuations, reaching a high level in days with low averages temperatures.

So, the most significant growths were recorded in 10 . 02. 2005-20. 02. 2005 with an affected area of 10.97-8.82 $=2.15$; and 11.03.2005-22.04. 2005 with growth differences of 14.67-13.32 = 1.35 (Tab. 1).

In Tab. 1 it can be can notice, as well, how affected areas grow in days with low minimum temperature. In some cases these values are small, but, yet, significant even in cold winter periods (08.06.2006).

Because luminosity parameters were not taken into consideration, it can be only assume that these growths of affected areas are favored, not only by low temperatures, but also by the lack of light. 
In case of strong luminosity and temperature growth, the plant has the capacity of defending against the pathogen agent through its own mechanisms. So, after a growing cycle of the affected area, a decrease of the attack follows, because of the plant's capacity to protect, sustained by higher temperatures.

These types of cycles can be observed in the case of growths shaped as concentric circles, owned to pathogen agents of Phoma, Phomopsis şi Coniothyrium.

\section{Conclusions}

This method is new and its use in phytopathology is original and can be demonstrated by using it in tracing the evolution of some affected areas of mycoses. The technique was first used in tracing affected area for Cactacee, but can be broadly used in phytopathology. The method which, according to the traced area, needs some changes, presents a wide adaptability. In the case of Cactace, there can be traced areas uncovered by pricks, such as the intercostal areas of columnar cacti or smooth areas for Opuntia species.

The great advantage of the method is represented by the possibility of using it in situ in the origin zones of species, or for crop plants in the field. Repeated images, made along a certain period of time, then overlapped, can provide us important data on the evolution of some affected areas.

The technique can be adapted in phytopathology and in the study of areas photographed with binocular lens or even the study of microscopic areas. (for example: conidial germination; growth of mycelium portions; forming of pathogen mushroom fructification e. g.).

\section{References}

Anderson, M. (1999). Ariocarpus cultivars: an overview of cristates, hybrids, monstruose forms and other oddities. Cactus and Succulent Journal (U.S.). 71 (4): 191-200.

Anson, A. E. (1982). A pseudomonad producing orange soft rot disease in cacti. Phytopatologische Zeitschrift. 103(2):163172.

Arnold, G. R. W. (1986). Lista de Hongos Fitopatogenos de Cuba. La Habana. Editorial Cientifico-Tecnica. Cuba.

Backeberg, C. (1958-1962). Die Cactaceae. Vol I-VI. Veb Gustav Fischer Verlang Jena.

Backeberg, C. (1966). Wunderwelt Kakteen. Veb Gustav Fischer Verlang Jena.

Backeberg, C. (1968). 1977. Das Kaktenlexicon. Veb Gustav
Fischer Verlang Jena.

Chase, A. R. (1982). Stem rot and shattering of Easter cactus caused by Dreschlera cactivora. Plant Disease, 66: 602-603.

Chavez, A. A. M. (1998). Incidencia de enfermedades en el nopal tunero (Opuntia amyclaea) en zona de San Martin de las Piramides, edo de Mexico. Tesis de licenciatuta. UNAMENEP Iztacala, Pp 93.

Copacescu, S. V. (2001). Cacti plants-Monograph (in Romanian). Editura Ceres, Bucuresti. Romania.

Feszt, Gy., L. Barbu-Tudoran and C. Craciun. (2006). Electronic microscopy research and numbering analyses of severl viroses at cacti plants, Botanical Garden Cluj-Napoca. Analele SNBC. Vegetal biology (in Romanian). XI(VI):538-553.

Gamal, G. D., M. M. Kheriza and H. M. El-beltagi (2004). Digital Quantification of fibrosis in liver biopsy sections: Description of a new method by PhotoShop Software. J. Gastroenterology and Hepatology. 19:78-85.

Gheban, D. (2005). Adobe PhotoShop like program of image analyses in patological anatomy (in Romanian). Romanian Patology Journal. 8(1/2):195-198.

Glang, M. (1993). Der Schwarze Pilz-ein Bisher Unerforschtes Krankheitsschadbild an Kakteen. Gymnos. 9 (18). 62-65.

Kobayashi, A. (2000). Cacti and Succulents in Japan, Part 4B, Chimeras and others. Cactus and Succulent Journal (U.S.). 72(2):71-79.

Miller, J. W. (1980). Fusarium blight and leaf spot of Christmas cactus. Plant Pathology Circular. 220, January.

Nakhutsrishvili, I. G. (1986). Flora Sporovâh Rastenii Gruzii (Konspect). Tbilisi; „Mețniereba”. Institut Botaniki imeni N. N. Kețhoveli. Akademia Nauk Gruzinskoi SSR. Ridings.

Nobel, P. S. (2002). Cacti, Biology and Uses. Cambridge University Press. New York.

Rosciglione, B. (1980). Ulteriori prove di lotta contra il „cancro gommoso" del fico d'India (Opuntia ficus - indica Miller) causato da Dothiorella ribis (Fuck.) Sacc., nell'isola di Limosa. Tecnica Agricola. 32(6):397-402.

Simay, E. I. (1987). A szurkepenesz (Botrytis cinerea Pers.). Kaktusz vilag. 1987(2):31-34.

Swart, W. J. and W. M. Kriel (2002). Pathogens associated with necrosis of cactus pear cladodes in South Africa. Plant Disease. 86:693.

Turner, R. M. (1992). Long-term saguaro population studies at Saguaro National Monument, p. 3-11. In: C. P. Stone, E. S. Bellantoni. (Eds.). Proceedings of the Symposium of Research in Saguaro National Monument. 